\title{
Effect of exercise on ventricular response to atrial fibrillation in Wolff-Parkinson-White syndrome
}

\author{
JONATHAN C P CRICK, D WYN DAVIES, ^ PHYLLIS HOLT, PAUL V L CURRY, \\ EDGAR SOWTON
}

From the Department of Cardiology, Guy's Hospital, London

SUMmaRY Ten patients with Wolff-Parkinson-White syndrome underwent cardiac electrophysiological study extended to include the induction of atrial fibrillation at maximum exercise in the upright position. This was performed using a new temporary bipolar lead with a helical active fixation tip for atrial pacing. The highest rate of atrioventricular conduction via the accessory pathway was greater during exercise than at rest in all 10 patients (mean increase $28 \%$ ). In three cases the resulting ventricular rate exceeded 300 beats/min, but no patient had severe symptoms or ventricular arrhythmias.

The exercise induced enhancement of accessory pathway conduction may significantly but unpredictably affect the risk from spontaneous atrial fibrillation especially in patients with coronary artery disease or in those taking antiarrhythmic drugs. The test procedure was sufficiently simple and well tolerated to be included in our routine electrophysiological investigation.

In patients with Wolff-Parkinson-White syndrome a spontaneous episode of atrial fibrillation may be conducted by the ventricles at a very high rate if the accessory pathway has a short refractory period. This can itself result in syncope and may progress to ventricular fibrillation. ${ }^{1-3}$ It is in an effort to assess this risk that in the cardiac programmed stimulation study the maximum rate of atrioventricular conduction via the accessory pathway is tested by rapid atrial pacing and induction of atrial fibrillation.

Recently, a young patient underwent such a study, which showed a maximum ventricular rate with atrial pacing, or in atrial fibrillation, of 130 beats/min. A few weeks later, however, he had an apparent syncopal attack while playing football. This led us to question whether the standard study, performed with the patient supine and at rest, was able to indicate the full extent of the risk in the ambulant patient.

We therefore extended the electrophysiological investigation to see if upright posture and exercise affected the behaviour of the accessory pathway. We

Requests for reprints to Dr Jonathan C P Crick, Department of Cardiology, Guy's Hospital, St Thomas Street, London SE1 9RT.

^Present address: Department of Cardiology, St Bartholomew's Hospital, London EC1A 7BE.

Accepted for publication 29 January 1985 report here the results of such studies in 10 patients with Wolff-Parkinson-White syndrome who were taking no drugs.

\section{Patients and methods}

The 10 subjects were selected from 13 consecutive patients undergoing investigation for WolffParkinson-White syndrome. Two were excluded from this analysis becuase they were taking antiarrhythmic drugs; one other patient developed disorganised ventricular activity with syncope during the resting programmed stimulation study so that further study during exercise was considered inappropriate. Seven were men, three women; their ages ranged from 14 to 47 (mean 29) years. All patients had electrocardiograms showing consistent delta waves and short PR intervals, and all had regular tachycardias either documented or strongly suggested by symptoms. The delta wave pattern indicated that the accessory pathway was left sided in four, right sided in two, and septal in four.

All patients underwent standard programmed stimulation studies including rapid atrial pacing and the induction of atrial fibrillation at rest. The findings established the potential for orthodromic tachycardia and confirmed that the site of the accessory pathway 


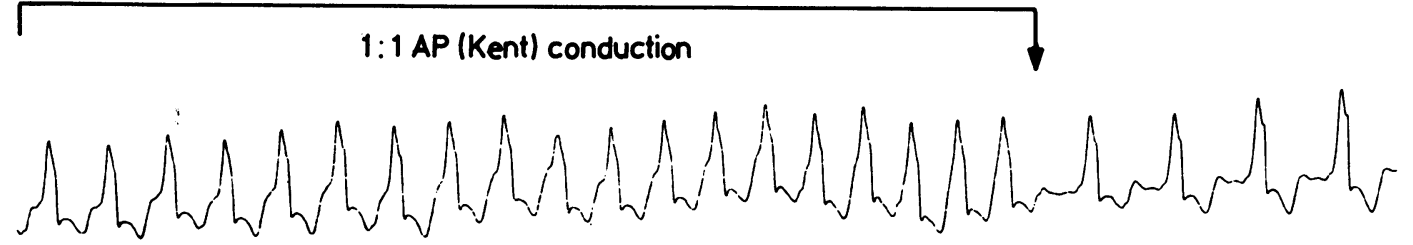

(b)

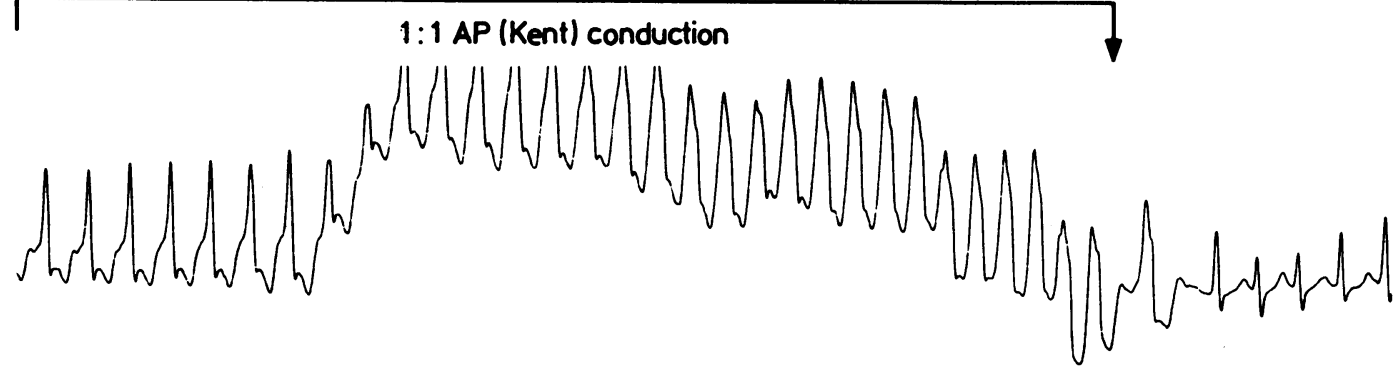

Fig. 1 Electrocardiograms recorded from the same patient during incremental atrial pacing when supine at rest (a) and during peak bicycle excercise in the upright position $(b)$. Loss of atrioventricular conduction via the accessory pathway $(A P)$ (arrowed) occuored at a rate of 240 beats/min at rest and at 330 beats/min during exercise. (In this patient (case 7) the highest rates were achieved during atrial fibrillation.)

had been correctly predicted from the electrocardiogram. No dual accessory pathways were evident.

One of the problems in extending the study to include atrial pacing on exercise is instability of the atrial electrode. We have used a new type of temporary pacing lead with active fixation (OSYPKA TU115S, Siemens-Elema (UK), Sunbury on Thames, Middlesex). It is a No 5 French gauge bipolar lead with a helical tip electrode and a removable stylet, which can be curved for positioning in the right atrium. The lead was inserted via the right subclavian vein in nine patients, in six at the time of the resting stimulating study, and in three as a separate procedure. In one patient with a left sided accessory pathway a standard bipolar electrode in the proximal coronary sinus, inserted via the subclavian vein, was left in place after the resting study and used for the exercise study.

All patients were exercised upright on the bicycle ergometer. The upright position was chosen because previous experience indicated that posture significantly affected the behaviour of re-entry tachycardias including the effective refractory period of the accessory pathway for retrograde conduction. 45

The bicycle ergometer was used rather than the treadmill because of the better quality electrocardiogram produced and the partial support given to the patient in case faintness developed. The electrocardiogram was monitored continuously as two external channels and right atrial electrogram. A lightweight portable programmed stimulator (Biotronik USM-30, Biotronik (UK) Ltd, Slough, Berkshire) was also connected to the atrial lead. Resuscitation facilities were immediately available, as were adequate personnel to manage the patient physically and medically should syncope occur.

Exercise was performed with workload increasing by $50 \mathrm{~W}$ every 2 minutes up to the maximum capability, in all cases limited by fatigue with sinus rates over 150 beats/min. During peak exercise atrial pacing was started and the rate increased until atrioventricular block occurred and atrial fibrillation was induced as confirmed by the atrial electrogram. Exercise was then stopped, and spontaneous reversion to sinus rhythm occurred in eight cases. One patient reverted to atrial flutter with 2:1 atrioventricular block and one to an orthodromic atrioventricular re-entry tachycardia at $170 \mathrm{beats} / \mathrm{min}$. They were converted to sinus rhythm by atrial pacing using burst overdrive and single timed extrastimulus respectively.

\section{Results}

The usual behaviour of atrioventricular conduction in Wolff-Parkinson-White syndrome was seen with incremental atrial pacing at rest: progressive widening of the QRS complexes with increasing pre-excitation. This was due to lengthening delay in the atrioven- 


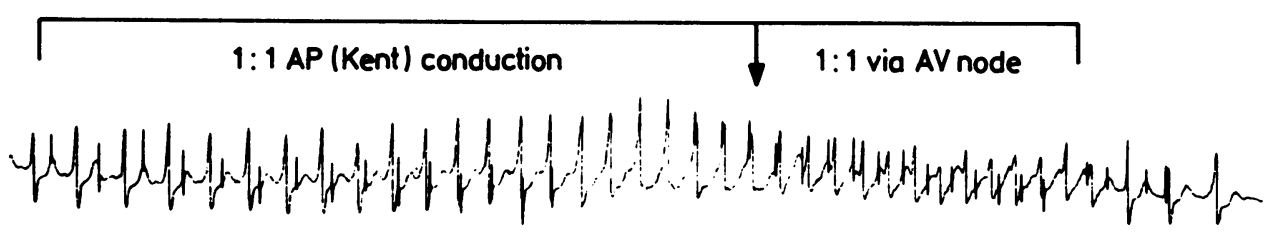

Fig. 2 Electrocardiogram showing the node dominant response to incremental atrial pacing during exercise. In this patient (case 4) the test was performed at submaximal exercise (chosen for illustration); $1: 1$ atrioventricular conduction was maintained via the atrioventricular $(A V)$ node up to a rate of 320 beats/min after conduction block in the accessory pathway ( $A P$ ) had developed at 290 beats/min (arrowed).

tricular node as shown by a decreasing HV interval associated with an increasing $\mathrm{AH}$ interval. At a rate determined by its refractory period there was sudden block in the accessory pathway resulting in either continued conduction, with delay, by the atrioventricular node and His bundle (which may be called "node dominant" behaviour) or the development of second degree atrioventricular block ("accessory pathway dominant"). Figure 1 shows an example of the latter behaviour, with block occurring at 220 beats/min.

With exercise, as the sinus rate increased, the delta wave became less apparent. This was associated with a shortening of the $\mathbf{P}$ to non-delta $\mathbf{R}$ wave interval and therefore presumably the atrioventricular nodal conduction time. On atrial pacing the reverse was seen with increasing pre-excitation and widening of the QRS interval at first progressively and then in some cases abruptly probably owing to block in the atrioventriuclar node, possibly bundle branch block. Atrioventricular conduction continued with little change in the stimulus to $R$ wave interval until in eight patients $2: 1$ block occurred in the accessory pathway. Figure 1 also shows this accessory pathway dominant pattern with block at a substantially higher rate ( 330 beats/min) than at rest in the same patient.

Figure 2 shows the node dominant behaviour seen in the other two patients during peak exercise. There was at first the usual increasing degree of preexcitation with atrial pacing; the delta wave then suddenly disappeared leaving a narrow $Q R S$ complex with a longer PR interval; $1: 1$ conduction continued, however, to a higher rate at which Wenckebach type block occurred. In these patients the highest rate of accessory pathway conduction was taken as the rate at which the loss of delta wave occurred.

As atrial pacing rate was increased further, atrial fibrillation was induced and conducted irregularly via the accessory pathway or atrioventricular node. In four patients at rest and in three during exercise the shortest interval between two similar pre-excited complexes during atrial fibrillation indicated a higher maximum forward conduction rate via the accessory pathway than seen during the incremental atrial pacing, suggesting that with these cases intra-atrial or pacemaker exit block had been the limiting factor.

The maximum rate of atrioventricular conduction by the accessory pathway was higher during exercise than at rest in all 10 patients. Thus even with this

Table Details of patients and results

\begin{tabular}{|c|c|c|c|c|c|c|c|}
\hline \multirow[t]{2}{*}{ Case No } & \multirow[t]{2}{*}{ Age (yr) } & \multirow[t]{2}{*}{ Sex } & \multirow[t]{2}{*}{$A P$ site ${ }^{\star}$} & \multirow{2}{*}{$\begin{array}{l}\text { Resting } \\
\text { maximum } A P+ \\
\text { (beats/min) }\end{array}$} & \multicolumn{3}{|l|}{ Exercise } \\
\hline & & & & & $\begin{array}{l}\text { SR‡ } \\
\text { (beats/min) }\end{array}$ & $\underset{\text { (beats/min) }}{\text { Maximum } A P t}$ & $\begin{array}{l}\% \text { Increase in } \\
\text { maximum } A P S\end{array}$ \\
\hline $\begin{array}{c}1 \\
2 \\
3 \\
4 \\
5 \\
6 \\
7 \\
8 \\
9 \\
10 \\
\text { Mean }\end{array}$ & $\begin{array}{l}14 \\
30 \\
31 \\
32 \\
38 \\
28 \\
16 \\
37 \\
18 \\
47 \\
29\end{array}$ & $\begin{array}{l}\mathbf{M} \\
\mathbf{F} \\
\mathbf{F} \\
\mathbf{F} \\
\mathbf{M} \\
\mathbf{M} \\
\mathbf{M} \\
\mathbf{M} \\
\mathbf{M} \\
\mathbf{M}\end{array}$ & $\begin{array}{l}\text { Right } \\
\text { Septal } \\
\text { Right } \\
\text { Left } \\
\text { Septal } \\
\text { Left } \\
\text { Left } \\
\text { Left } \\
\text { Septal } \\
\text { Septal }\end{array}$ & $\begin{array}{l}130(\mathrm{~N}) \\
240 \\
215 \\
260 \\
230 \\
230(\mathrm{~F}) \\
240(\mathrm{~F}) \\
240(\mathrm{~F}) \\
270(\mathrm{~F}) \\
230 \\
229\end{array}$ & $\begin{array}{l}150 \\
160 \\
185 \\
175 \\
175(\text { AF) } \\
175 \\
180 \\
160 \\
170 \\
160 \\
169\end{array}$ & $\begin{array}{l}200(\mathrm{~N}) \\
300 \\
260 \\
330(\mathrm{~N}) \\
255(\mathrm{~F}) \\
290(\mathrm{~F}) \\
350(\mathrm{~F}) \\
310 \\
300 \\
300 \\
290\end{array}$ & $\begin{array}{l}54 \\
25 \\
21 \\
27 \\
11 \\
26 \\
46 \\
31 \\
11 \\
30 \\
28\end{array}$ \\
\hline
\end{tabular}

$\star$ AP site, site of accessory pathway.

-Maximum AP, maximum rate of anterograde conduction via the accessory pathway (N, node dominant; $F$, in atrial fibrillation). $¥ S R$, sinus rate on exercise just before atrial pacing (AF, atrial flutter with $2: 1$ block).

SPercentage increase in maximum rate of anterograde conduction via the accessory pathway during upright exercise compared with resting supine. 


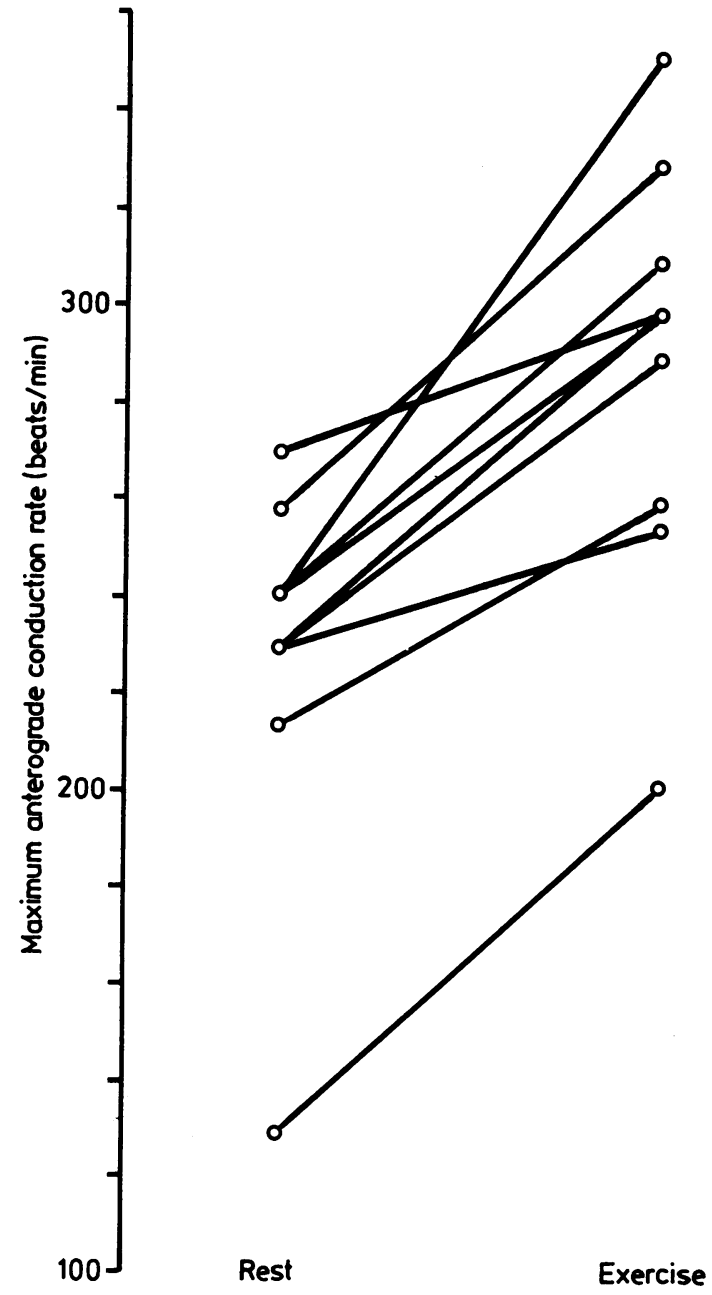

Fig. 3 Individual results from 10 patients showing maximum anterograde conduction rate via the accessory pathway when supine at rest and during peak exercise.

small number the result is statistically highly significant $(p<0.002)$. The Table and Fig. 3 show the individual results; the mean increase was $28 \%$, range $11 \%$ to $54 \%$.

In three patients the maximum rate during exercise exceeded 300 beats/min. There was, however, no disorganised ventricular activity, and, although one patient felt moderately faint, all were able to continue pedalling unaided. Most reported that their symptoms were much milder than those produced by incremental atrial pacing during the original resting study.

The procedure resulted in no other complications: in particular, no patients developed symptoms or signs of myocardial perforation with the use of the active fixation leads.

\section{Discussion}

The aims of these studies were twofold: the practical and the scientific. The primary aim was to answer the practical question: is the patient at risk of circulatory collapse or ventricular fibrillation if atrial fibrillation were to occur spontaneously during exercise? The second question was whether exercise had an appreciable effect on the refractory period of the accessory pathway in patients with consistent pre-excitation. Although this has not to our knowledge been tested before, there is some indirect evidence of enhancement of anterograde accessory pathway conduction by exercise.

In a previous study from this laboratory, of tachycardia termination windows, two patients had Wolff-Parkinson-White syndrome and orthodromic tachycardias. ${ }^{4}$ In these, ventricular extrastimuli showed a shorter retrograde refractory period in the accessory pathway with upright posture and exercise resulting in the shrinking or disappearance of the termination window. A result of sustained tachycardia has also been shown by Curry et al to be a shortening of accessory pathway refractoriness, ${ }^{5}$ although the mechanism for this probably involves a direct effect of the rate as well as haemodynamic reflexes. Hammill et al recently described two patients in whom orthodromic tachycardia could be sustained only in the upright position, ${ }^{6}$ although it was not stated whether block occurred in the normal or the accessory pathway when supine.

There have been several studies in which exercise seemed to facilitate ventricular pre-excitation in sinus rhythm in patients with intermittent preexcitation. ${ }^{7-10}$ In other similar cases, however, exercise has resulted in block in the accessory pathway ${ }^{7} 111$ : this block was probably caused by the increase in sinus rate as shown by both the similar effect of atropine in two ${ }^{711}$ and the opposite effect of carotid massage. ${ }^{12}$

An increase in the maximum rate of conduction through the accessory pathway could be expected to be caused by stimulation of adrenoreceptors in the pathway either by circulating catecholamines or by increased tone in the sympathetic innervation. Isoprenaline infusion has been shown to cause recovery of pre-excitation in five patient in whom it had disappeared either spontaneously or after antiarrhythmic treatment. ${ }^{12}$ More important to this study are the findings of Wellens et al, who measured the effective refractory period of the accessory pathway in seven patients with Wolff-Parkinson-White syndrome and found that in six it shortened after an infusion of iso- 
prenaline. ${ }^{13}$ The measurements were made during pacing at a constant rate to avoid any direct rate effect. Cosio et al reported a patient presenting with ventricular fibrillation while playing racquet ball, in whom isoprenaline reduced the shortest pre-excited $R R$ interval in atrial fibrillation from 270 to $180 \mathrm{~ms}^{14}$

Our results confirm that exercise combined with upright posture significantly increases the maximum rate of atrioventricular conduction via the accessory pathway. The degree of increase, however, varied widely between patients and was not related to age or the site of the pathway.

The haemodynamic tolerance to ventricular rates of up to 350 beats/min during exercise was an unexpected finding. It contrasts with our usual experience that some patients at rest feel severely faint at lower rates, sometimes below 200 beats/min, despite the lower requirement for cardiac output. The difference could be due to catecholamine induced short systole and rapid myocardial relaxation combined with increased venous return from the active leg muscles. The benefits of these mechanisms could be lost should myocardial ischaemia or ventricular failure occur. Thus an important factor in the ability of the study patients to sustain an adequate circulation and continue exercising with high ventricular rates may be the low age of this group and the presumed absence of coronary artery disease. Tolerance of the high rates may also be impaired by drugs which prolong systole or otherwise exert a negative inotropic effect; this could outweigh the intended benefit of prolonging the refractory period of the accessory pathway.

The haemodynamic tolerance may be a major factor determining the risk of ventricular fibrillation. In the context of the first aim of the study the tests were all negative, in that none of the patients had serious symptoms or ventricular arrhythmias in response to the atrial fibrillation. The patient whose collapse prompted the study developed no symptoms during the test but had a vasovagal faint in sinus rhythm after stopping exercise. It should not be concluded from these negative findings that exercise may not in some cases increase the risk from spontaneous atrial fibrillation as the number of patients is low and the proportion of patients with Wolff-Parkinson-White syndrome who have a dangerously short anterograde accessory pathway refractory period is quite small. ${ }^{3}$

The wide variation between patients in the degree of rate increase was not related to age or the site of the pathway. Moreover, the compensatory haemodynamic responses are determined by several factors that are not readily predictable. Only testing the individual patient can, therefore, determine what additional risk, if any, exercise may entail for that patient. We found that the simple stimulation test during exercise was practicable and rather less traumatic for the patient than the resting study, allowing us to incorporate it in our routine clinical investigation. Although the prognostic significance of the degree of rate increases with exercise is at present uncertain, the development of syncope or ventricular arrhythmias with this manoeuvre would indicate a need for medical or surgical intervention and a further test to check that the intervention was in fact successful.

It is perhaps paradoxical that patients with electrocardiographic evidence of pre-excitation are generally submitted to programmed stimulation studies only after they have suffered suspected tachycardias. In the case of orthodromic tachycardias our experience suggests that the initiation usually depends on a premature atrial depolarisation conducted anterogradely only via the atrioventricular node followed by retrograde conduction via the accessory pathway: this condition is more likely where the accessory pathway has a longer refractory period. In the case where the presenting tachycardia is atrial fibrillation, the patient's survival has already shown a relatively low risk. It may thus be that patients with pre-excitation and no history of palpitation include some of those most at risk of sudden death.

\section{References}

1 Ahlinder S, Granath A, Holmer S, Mascher G. WolffParkinson-White syndrome med paroxysmalt atrieflimmer övergäende i ventrikelflimmer. Framgängsrik behandling med extern hjartmassage och defibrillering. Nord Med 1963; 70: 1336-9.

2 Dreifus LS, Haiat R, Watanabe Y, Arriaga J, Reitman $\mathrm{N}$. Ventricular fibrillation: a possible mechanism of sudden death in patients with Wolff-Parkinson-White syndrome. Circulation 1971; 43: 520-7.

3 Klein GJ, Bashore TM, Sellers TD, Pritchett ELC, Smith WM, Gallagher JJ. Ventricular fibrillation in the Wolff-Parkinson-White syndrome. $N$ Engl F Med 1979; 301: 1080-5.

4 Crick JCP, Way B, Kappenberger L, Sowton E. Variation in tachycardia termination window with posture and exercise. In: Feruglio GA, ed. Cardiac pacingelectrophysiology and pacemaker technology. Padova: Piccin Medical Books, 1983: 273-6.

5 Curry PVL, Rowland E, Fox KM, Krikler DM. The relationship between posture, blood pressure and electrophysiological properties in patients with paroxysmal supraventricular tachycardia. Arch Mal Coeur 1978; 71: 293-9.

6 Hammill SC, Holmes DR, Wood DL, et al. Electrophysiologic testing in the upright position: improved evaluation of patients with rhythm disturbances using a tilt table. 7 Am Coll Cardiol 1984; 4: 65-71.

7 Averill KH, Fosmoe RJ, Lamb LE. Electrocardiographic findings in asymptomatic subjects: IV. WolffParkinson-White syndrome. Am f Cardiol 1960; 6: 10829. 
8 Sandberg L. The effect of exercise on the electrocardiogram of pre-excitation. Acta Med Scand 1961; suppl 365: 88-105.

9 Horio Y, Matsuyama K, Morikami Y, et al. Blocking effect of verapamil on conduction over a catecholaminesensitive bypass tract in exercise-induced WolffParkinson-White syndrome. J Am Coll Cardiol 1984; 4: 186-91.

10 Wolff L, Parkinson J, White PD. Bundle-branch block with short $\mathrm{P}-\mathrm{R}$ interval in healthy young people prone to paroxysmal tachycardia. Am Heart f 1930; 5: 685-704.

11 Strasberg B, Ashley WW, Wyndham CRC, et al. Treadmill exercise testing in the Wolff-Parkinson-White syndrome. Am $\mathcal{F}$ Cardiol 1980; 45: 742-8.
12 Przybylski J, Chiale PA, Halpern MS, Nau GJ, Elizari MV, Rosenbaum MB. Unmasking of ventricular preexitation by vagal stimulation or isoproterenol administration. Circulation 1980; 61: 1030-7.

13 Wellens HJJ, Brugada P, Roy D, Weiss J, Bär FW. Effect of isoproterenol on the anterograde refractory period of the accessory pathway in patients with the Wolff-Parkinson-White syndrome. Am f Cardiol 1982; 50: $180-4$.

14 Cosio FG, Benson DW Jr, Anderson RW, et al. Onset of atrial fibrillation during antidromic tachycardia: association with sudden cardiac arrest and ventricular fibrillation in a patient with Wolff-Parkinson-White syndrome. Am f Cardiol 1982; 50: 353-9. 